\title{
«LA NATURALEZA VIVA DEBE OCUPAR EL PRIMER PLANO». UN ESTUDIO SOBRE EL DICCIONARIO DE PEDAGOGÍA (1936) DE EDITORIAL LABOR Y LA ENSEÑANZA DE LAS CIENCIAS FÍSICO-QUÍMICAS Y NATURALES ${ }^{\alpha}$
}

\author{
"Living nature must be to the fore". A study of the Dictionary \\ of Pedagogy (1936) by the publisher Editorial Labor and the \\ teaching of physics, chemistry and natural sciences
}

\section{Mavi Corell Domenech ${ }^{\beta}$}

Fecha de recepción: 24/12/2020 • Fecha de aceptación: 16/03/2021

Resumen. Abordamos el estudio de uno de los grandes proyectos de Editorial Labor de Barcelona, el Diccionario de pedagogía de 1936, desde una perspectiva novedosa: el análisis de las entradas sobre enseñanza de las materias científicas. El estudio del ser vivo en su entorno con una perspectiva ecológica, tanto fuera del aula, en excursiones, como dentro, mediante acuarios, terrarios, herbarios y huertos escolares constituye el centro de las metodologías propuestas por la obra, en la que observamos la influencia de los principios escolanovistas, el Nature study y la Institución Libre de Enseñanza. Coordinado por el maestro Luis Sánchez Sarto, el Diccionario recogió el estado de la pedagogía y la educación mundial. Contó con un centenar de autores anónimos, la mayor parte alemanes, austriacos, americanos y españoles. John Dewey, Vilhelm Rasmussen y Georg Kerschensteiner constituyen, asimismo, referentes pedagógicos del Diccionario en la enseñanza de las ciencias. En este artículo ofrecemos argumentos que apuntan a Margarita Comas Camps

\footnotetext{
${ }^{\alpha}$ El presente trabajo ha sido desarrollado en el marco del proyecto de investigación «Desafíos educativos y científicos de la Segunda República española: internacionalización, popularización e innovación en universidades e institutos» [PGC2018-097391-B-I00], financiado por el Ministerio de Ciencia e Innovación en el marco del programa estatal de Generación del Conocimiento y Fortalecimiento Científico y Tecnológico del Sistema I+D+i 2017-2020.

${ }^{\text {B }}$ Unidad de Educación, Florida Universitària. Carrer del Rey En Jaume I, 2, 46470 Catarroja (València, España). Correo electrónico: mcorell@florida-uni.es
}

Cómo citar este artículo: Corell Domenech, Mavi. "La naturaleza viva debe ocupar el primer plano". Un estudio sobre el Diccionario de Pedagogía (1936) de editorial Labor y la enseñanza de las ciencias físico-químicas y naturales». Historia y Memoria de la Educación 14 (2021): 451-486 
y a Rafael Candel Vila como autores de las dos entradas sobre metodología de enseñanza de las ciencias de la obra.

Palabras clave: Diccionario de pedagogía (1936); Editorial Labor; Escuela Nueva; historia de la enseñanza de las ciencias naturales; Rafael Candel Vila; Margarita Comas Camps.

Abstract. We present the study of one of the great projects of the Barcelona publisher Editorial Labor, namely the Diccionario de Pedagogía (1936), from a new perspective: the analysis of entries on the teaching of scientific subjects. The axis of the methodologies proposed by the work is the study of living things in their natural environment from an ecological perspective, both outside the classroom via excursions and inside through aquaria, terraria, herbaria and school kitchen gardens. These methodologies can be seen to have been be influenced by New Education principles, the Nature Study movement and the Spanish Institución Libre de Enseñanza. Coordinated by Luis Sánchez Sarto, the Diccionario de Pedagogía recorded the state of pedagogy and education worldwide, counting on a hundred or so anonymous authors most of whom were German, Austrian, American or Spanish. John Dewey, Vilhelm Rasmussen and Georg Kerschensteiner are the dictionary's pedagogical references in science teaching. In our article, we present arguments suggesting that Margarita Comas Camps and Rafael Candel Vila were the authors of the dictionary's two entries on teaching methodology.

Keywords: Diccionario de pedagogía (1936); Editorial Labor; New Education; history of natural science teaching; Rafael Candel Vila; Margarita Comas Camps.

\section{INTRODUCCIÓN}

Las revisiones de la situación de la didáctica de las ciencias que se realizaron durante la Transición española ${ }^{1}$ afirmaban que hasta los años 80 del siglo pasado había un vacío prácticamente total en la investigación en este campo de estudio en España. Estas perspectivas no tuvieron en cuenta las aportaciones del profesorado de ciencias que desde finales de siglo XIX y durante el primer tercio del XX, con especial intensidad durante los gobiernos de la Segunda República, desarrollaron un conjunto de propuestas para renovar la enseñanza de las materias científicas bajo la influencia de la Escuela Nueva y la nueva pedagogía. Si bien se podrían considerar aportaciones pre-teóricas o pre-paradigmáticas, es decir, no integradas todavía en un corpus disciplinar, el análisis de

1 Durante este periodo histórico, entre 1975 y 1982, se restauró la democracia en España. 
estos primeros pasos puede ayudarnos a comprender la situación actual de la disciplina. ${ }^{2}$ Asimismo, el estudio de la didáctica de las ciencias desde su historia y la recuperación de la memoria histórica ${ }^{3}$ constituyen una rica fuente de experiencias y materiales didácticos para la formación personal y profesional de los docentes. ${ }^{4}$

En relación al análisis histórico de la ciencia como disciplina escolar en el periodo republicano, contamos con algunas tesis de doctorado y estudios posteriores que han recuperado los inicios de la didáctica de las ciencias como campo de estudio, como el de José M. Bernal sobre la renovación de la enseñanza de las ciencias en la educación primaria en España (1882-1936) o el de M. a Ángeles Delgado Martínez que abordó la contribución de las mujeres a la construcción de la didáctica de las ciencias en España durante las primeras décadas del siglo XX.5

Trabajos más recientes, como los de Leoncio López-Ocón, Santiago Aragón, Víctor Guijarro y Mario Pedrazuela, han puesto de manifiesto el valor de las aportaciones de los profesores de enseñanza secundaria a la innovación educativa y a la renovación de los artefactos de la enseñanza de la ciencia durante este periodo. ${ }^{6}$ Los estudios de Delgado sobre

\footnotetext{
2 José M. Bernal ofrece información pormenorizada de las mencionadas revisiones del estado de la didáctica de las ciencias en Renovación pedagógica y enseñanza de las ciencias. Medio siglo de propuestas y experiencias escolares (1882-1936) (Madrid: Biblioteca Nueva, 2001), 15-22.
}

3 Fernández Soria analiza el desmantelamiento de la educación republicana y la destrucción de la moderna pedagogía española derivada de lo que denomina «exilio pedagógico de sus protagonistas» que trajo la guerra civil española (1936-1939) y el régimen franquista. Juan Manuel Fernández Soria, «La destrucción de la modernidad republicana. (Sin)razones del exilio pedagógico español», Historia y Memoria de la Educación 9 (2019): 61-99.

4 Miguel de Guzmán, «Tendències innovadores en educació matemàtica». Butlletí de la Societat Catalana de Matemàtiques 7 (1992): 7-33. Pedro Miguel Gónzalez Urbaneja, «La historia de las matemáticas como recurso didáctico e instrumento para enriquecer culturalmente su enseñanza», Suma (febrero 2004): 17-28.

5 Bernal, Renovación pedagógica. M. ${ }^{a}$ Ángeles Delgado Martínez, Científicas y educadoras. Las primeras mujeres en el proceso de construcción de la Didáctica de las Ciencias en España (Murcia: Editum, Ediciones de la Universidad de Murcia, 2009).

${ }^{6}$ Leoncio López-Ocón, Víctor Guijarro y Mario Pedrazuela, eds., Aulas abiertas. Profesores viajeros y renovación de la enseñanza secundaria en los países ibéricos (1900-1936) (Madrid: Universidad Carlos III de Madrid, 2018); Víctor Guijarro Mora, Artefactos y acción educativa. La cultura del objeto científico en la enseñanza secundaria en España (1845-1930) (Madrid: Dykinson, 2018); Leoncio LópezOcón, ed., Aulas modernas: Nuevas perspectivas sobre las reformas de la enseñanza secundaria en la época de la JAE (1907-1939) (Madrid: Universidad Carlos III de Madrid, 2014); Leoncio López-Ocón, "La educación en la Segunda República (1931-1936): De visiones de conjunto a estudios de caso», en Política cultural de la segunda República, eds. I. Murga y J. M. López (Madrid: Fundación Pablo 
Margarita Comas, ${ }^{7}$ así como la tesis de doctorado de Luis Moreno sobre Modesto Bargalló, ${ }^{8}$ han aportado las biografías y los trabajos en el ámbito de la enseñanza de las ciencias de dos destacados profesores normalistas republicanos.

La bibliografía actual suele atribuir las iniciativas para el proyecto de renovación de la enseñanza de las ciencias a la Institución Libre de Enseñanza (ILE), así como a las becas de la Junta para Ampliación de Estudios (JAE) que permitieron a los docentes españoles estudiar temas pedagógicos, asistir a congresos y conocer las prácticas innovadoras que se estaban desarrollando en los países del ámbito europeo. El centenar de pensionados que recibieron estas ayudas publicaron alrededor de cuatrocientas obras, relativas a material escolar, métodos de enseñanza y didáctica de las materias. ${ }^{9}$

Menos consideración han tenido las editoriales que divulgaron estas experiencias y las traducciones de los pedagogos del ámbito europeo y de Estados Unidos, entre las que se encontraban las dedicadas a temas científicos. Estas empresas contribuyeron a la internacionalización de la pedagogía española y a la formación científica del colectivo magisterial que los republicanos consideraban un elemento determinante en su proyecto de renovación del país a través de la educación.

Iglesias, 2016), 171-198; Leoncio López-Ocón, Santiago Aragón y Mario Pedrazuela (eds.), Aulas con memoria. Ciencia, educación y patrimonio en los institutos históricos de Madrid (1837-1936) (Madrid: Doce Calles, 2012).

7 Sobre Comas ver María Ángeles Delgado, Margalida Comas Camps (1892-1972), científica y pedagoga (Palma de Mallorca: Govern de les Illes Balears, 2014); Margarita Comas, Escritos sobre ciencia, género y educación. Edición de José M. Bernal y Francisca Comas (Madrid: Biblioteca Nueva, 2001).

8 Ver Luis Moreno Martínez, «Ciencia en las aulas: Prácticas pedagógicas, cultura material e historia de la ciencia en la obra de Modesto Bargalló en España (1894-1939)» (Tesis doctoral, Universitat de València, 2020) y Luis Moreno Martínez, «Modesto Bargalló en España (1894-1939): una biografía entre la historia de la educación y la historia de la ciencia», Historia y Memoria de la Educación 13 (2021): 635-674. Ver también el trabajo de José Pedro Marín sobre la relación de los materiales didácticos y la enseñanza de las ciencias en «Categorización de los materiales didácticos para la enseñanza de los seres vivos en los antiguos gabinetes y laboratorios», Cabás 21 (junio 2019): 1-22, así como sobre la enseñanza de la botánica, José Pedro Marín y María José Martínez, «Froebel and the teaching of botany: the garden in the Kindergarten Model School of Madrid», Paedagogica Historica 56, 1-2 (2020): 200-216.

9 En Teresa Marín Eced, «La pedagogía europea importada por los becarios de la JAE (1907-1937)», Historia de la Educación 6 (1987): 261-278. 
Editorial Labor, desde su fundación en 1915 por un alemán afincado en Barcelona, trajo a España algunas de las grandes obras de la pedagogía europea. ${ }^{10}$ En este trabajo se ofrece el análisis de las entradas sobre enseñanza de las materias científicas de uno de sus grandes proyectos, el Diccionario de pedagogía de 1936, un hito de la bibliografía pedagógica de la época escasamente explorado. ${ }^{11}$

Coordinada por el maestro y licenciado en Filosofía y Letras Luis Sánchez Sarto y gestionado por su hermano, el economista republicano Manuel, ${ }^{12}$ esta obra recogió el estado de la pedagogía mundial. Consta de dos volúmenes, contiene 966 entradas escritas por 111 autores anónimos con una amplia representación internacional -40 alemanes y austríacos, 43 españoles, 18 americanos y latinoamericanos y 10 autores de otras procedencias-, ${ }^{13}$ cuyos nombres y filiaciones aparecen indexados al comienzo de la obra, 751 fotografías en blanco y negro, índices alfabéticos (analítico y onomástico) de entradas y una amplia selección

10 En 1937 Labor tenía sedes en Río de Janeiro, Buenos Aires, Madrid y Barcelona. Sobre Editorial Labor ver José Martínez de Sousa, Antes de que se me olvide. Una aventura personal y bibliológica personal e intransferible (Gijón: Editorial Trea, 2005) y Conrad Vilanou Torrano, "Joaquín Roura Parella (1897-1983) y los orígenes de la Pedagogía Universitaria en Cataluña», en Pedagogía y Educación en el siglo XXI, ed. J. Ruiz Berrio (Madrid: Universidad Complutense, 2005), 171-202.

11 Entre los trabajos que han tenido en consideración esta obra figuran: Fania Herrero, Alejandra Ferrándiz, Enrique Lafuente y José Carlos Loredo, «Psicología y Educación en la II República y en la España de Franco: un estudio a través del Diccionario de pedagogía de Labor $(1936,1964)$ », Revista de Historia de la Psicología 22, no. 3-4 (2001): 367-381. Alejandra Ferrándiz, José C. Loredo y Enrique Lafuente, «Psicología y educación en la España de la II República: Un estudio a través del Diccionario de Pedagogía Labor (1936)», Revista de educación 328 (2002): 451-463. Julio Mateos Montero, «Huellas pedagógicas alemanas en España. Una aproximación histórica», Magazin 20, (2011): 26-33. Antón Costa y María Eugenia Bolaño, «El Diccionario de Pedagogía de Labor, Barcelona (1936): la construcción icónico-textual de un discurso pedagógico ligado a los ideales de la Escuela Nueva», Cadernos de História da Educação 17, no. 2 (2018): 380-398.

12 Manuel Sánchez Sarto en los inicios de su exilio provocado por la guerra civil manifestó predilección por las disciplinas científicas con la edición de la revista Ciencia, así como numerosos libros científico-técnicos en la editorial Atlante, una contribución a la difusión de la ciencia y la técnica española que se prolongó durante dos décadas, según ha expuesto López-Ocón en «La enciclopedia de la editorial Atlante: un proyecto ¿frustrado? del exilio republicano en 1939», en Arte, ciencia y pensamiento del exilio republicano español de 1939, eds. M. Cabañas, I. Murga, Miguel Á. PuigSamper y A. Sánchez (Madrid: Ministerio de la Presidencia, Relaciones con las Cortes y Memoria Democrática, 2020), 217-240; y en «Atlante: actores y etapas de una editorial republicana hispanoamericana», en El exilio español del 39 en México. Mediaciones entre mundos, disciplinas y saberes, eds. A. Sánchez y G. Zermeño (México, D.F.: El Colegio de México. Centro de Estudios Históricos, 2014), 63-100. Sobre Manuel Sánchez Sarto ver también Manuel Sánchez Sarto, Escritos económicos. México (1939-1969). Edición de Eloy Fernández Clemente (Zaragoza: Prensas Universitarias de Zaragoza, 2003).

13 Costa y Bolaño (2018), «El Diccionario de Pedagogía de Labor», 385. 
bibliográfica al final de cada entrada. En 1964 Labor publicó una segunda edición dirigida por el pedagogo Víctor García de la Hoz.

Según el listado de autores que aparece en sus primeras páginas, dos especialistas pudieron haber escrito las entradas sobre enseñanza de las materias científicas: la pedagoga y científica Margarita Comas Camps (1892-1972), profesora de ciencias de la Escuela Normal de la Generalitat de Cataluña; y Rafael Candel Vila14 (1903-1976), destacado cristalógrafo, mineralogista y geoquímico profesor del Institut-Escola Ausiàs March de Barcelona. ${ }^{15}$

Como señala Francisco Javier Pérez, la selección de los términos de una publicación de estas características no es arbitraria, sino que ilustra unos determinados "procesos sociales, debates de ideas, afectividades, mentalidades y visiones del mundo». ${ }^{16}$ Con el fin de valorar estas cuestiones, así como sus aportaciones y referentes, analizamos las entradas sobre enseñanza de las materias científicas del Diccionario de pedagogía de 1936. Nos planteamos identificar los contenidos -saberes, conocimientos, destrezas, técnicas, habilidades-, la argumentación sobre su valor formativo y utilidad, así como las prácticas profesionales ${ }^{17}$ de la enseñanza de las ciencias en esta obra.

En los últimos años el estudio de la ciencia en las aulas se ha consolidado como una línea de trabajo de la historia de la ciencia. Trabajos

\footnotetext{
14 Sobre Rafael Candel Vila ver Leoncio López-Ocón, «La trayectoria de 55 docentes de institutos españoles pensionados por la JAE», en Aulas abiertas. Profesores viajeros y renovación de la enseñanza secundaria en los países ibéricos (1900-1936), eds. Leoncio López-Ocón, Víctor Guijarro y Mario Pedrazuela (Madrid: Universidad Carlos III de Madrid, 2018), 443-454.

15 Centro fundado en 1932 en Barcelona siguiendo el modelo del Instituto-Escuela de la Junta para Ampliación de Estudios (JAE) (1907-1939) en Madrid. Sobre el Instituto-Escuela ver Encarnación Martínez, Leoncio López-Ocón, Gabriela Ossenbach, eds., Ciencia e innovación en las aulas. Centenario del Instituto-Escuela (1918-1939) (Madrid: CSIC, 2018).

16 Francisco Javier Pérez Hernández, «Preámbulo», en Diccionarios, discursos etnográficos, universos léxicos: propuestas teóricas para la comprensión cultural de los diccionarios (Caracas: Fundación Centro de Estudios latinoamericanos Rómulo Gallegos; Universidad Católica André Bellos, 2000), 5. Sobre el uso del diccionario como fuente primaria ver también Javier Pérez Hernández, Pensar y hacer el diccionario. Nociones de lexicografía: definiciones, géneros, crítica e historia. Criterios para elaborar diccionarios, métodos de investigación y bibliografía lexicográfica (Venezuela: Los Libros de el Nacional, 2005).

17 Elementos que Antonio Viñao indica para el análisis de la historia de las disciplinas escolares. Antonio Viñao, «La historia de las disciplinas escolares», Historia de la Educación 25 (2006): 243-269.
} 
como los de Rudolf, Olesko, Kaiser, Warwick y Bensaude-Vincent ${ }^{18}$ han analizado la educación y sus procesos con una perspectiva que va más allá de la relación lineal y jerarquizada entre los que, en principio, saben, los profesores, y los que no saben, el alumnado. La historia de la enseñanza de las disciplinas científicas ha mostrado cómo las prácticas docentes, la cultura material y visual, los materiales didácticos, los espacios y los instrumentos de evaluación configuran el aula de ciencias del pasado.

Asimismo, son de interés en este trabajo las aportaciones de Del Pozo Andrés que ha apuntado la necesidad de realizar estudios en profundidad sobre cómo se integraron las prácticas tradicionales con las de la nueva pedagogía, con el fin de dilucidar las actitudes de los docentes y las limitaciones de la aplicación de los métodos de la Escuela Nueva en España. ${ }^{19}$ En este sentido, el Diccionario de pedagogía constituye una fuente de interés como proyecto de compilación de las propuestas pedagógicas para la enseñanza de las ciencias, que se desarrollaron con especial intensidad a partir de la década de 1920, interrumpido por la guerra civil española (1936-1939).

\section{LAS EDITORIALES DE MADRID Y BARCELONA, CENTROS DE INNOVACIÓN EDUCATIVA}

Los dos centros de esta renovación pedagógica, ubicados a comienzos del siglo XX en Madrid y Barcelona, estaban asociados a empresas editoriales. En la capital, la Revista de Pedagogía (1922-1936), dirigida por Lorenzo de Luzuriaga, divulgó activamente los principios y metodologías activas de la Escuela Nueva y se convirtió en el órgano del movimiento en España. Por su parte, Francisco Beltrán Librería Española y Extranjera (1909-1935) asumió la edición de las obras de Adolphe

\footnotetext{
18 John L. Rudolph, How We Teach Science? What's changed and why it matters (Cambridge, Massachusetts: Harvard University press, 2019); Katherine Olesko, «Science Education in the Historical Study of Sciences», en International Handbook of research in History, Philosophy and Science Teaching, ed. M. R. Matthewsed (Dordrecht: Springer, 2014), 1965-1990; David Kaiser (ed.), Pedagogy and the Practice of Science. Historical and Contemporary Perspectives (Londres: MIT Press, 2005); Bernardette Bensaude-Vincent, José Ramón Bertomeu-Sánchez y Antonio García Belmar, L'émergence d'une science des manuels. Les libres de chimie en France (1789-1852) (París: Editions des Archives Contemporaines, 2003).

19 María del Mar del Pozo Andrés, «La Escuela Nueva en España: crónica y semblanza de un mito». Historia de la Educación 22-23 (2003-2004): 317-346.
} 
Ferrière en España ${ }^{20}$ que tradujo su director, Rodolfo Tomás Samper. En Barcelona, Editorial Labor colaboraba con un grupo de profesores de la Universidad de Barcelona, de Escuelas Normales y de Enseñanza Secundaria, comprometidos con el cambio educativo, que tradujeron al español las obras de los pedagogos de la Escuela Nueva. ${ }^{21}$

A la internacionalización de la pedagogía española contribuyó el viaje del pedagogo suizo Adolphe Ferrière por España, Latinoamérica y Portugal en 1930 que, como han señalado Quintino Lopes y Soler Mata, eligió Barcelona y Madrid como punto de comienzo y final de su periplo. ${ }^{22}$ Su visita a España tenía como objetivo revisar la penetración del movimiento de la Escuela Nueva y la edición de sus obras en español. Tomás Samper y Lorenzo Luzuriaga fueron las dos personas con las que más se relacionó durante la visita, el primero como su editor, y el segundo como líder de la Liga española de la Escuela Nueva afiliada a la Liga Internacional del movimiento escolanovista. ${ }^{23}$

Madrid y Barcelona compartieron traductores y autores, como es el caso de Margarita Comas, que colaboraba con la Revista de Pedagogía y con Labor, pero también rivalizaron. Llama la atención que, siendo Luzuriaga uno de los exponentes más destacados de la Escuela Nueva en España, no participara en el Diccionario de pedagogía ni se le dedicara una entrada. Luzuriaga, casi treinta años después en su propio Diccionario de

20 Esta editorial en 1920 dio a conocer en España la versión de 1915 de los principios de la Liga en el libro del pedagogo portugués Faria de Vasconcellos, Una escuela nueva en Bélgica, traducida al español por Domingo Barnés, último director del Museo Pedagógico Nacional tras la muerte de Manuel Bartolomé Cossio a fínales de 1935. Faria de Vasconcellos dirigió la escuela belga de Bierges-lez-Wawre, de 1912 a 1914, calificada por Adolphe Ferrière como «Escuela de nuevo tipo». José María Hernández Díaz ha indicado que la obra de la Vasconcellos tuvo una gran influencia en la pedagogía de la época. José María Hernández Díaz, «La pedagogía belga y la innovación educativa en España (1900-1936)», en Influencias belgas en la educación española e iberoamericana, ed. J. M. Hernández Díaz (Salamanca: Ediciones de la Universidad de Salamanca, 2019), 149-187.

21 Vilanou Torrano. «Joaquín Roura Parella», 171-202.

22 Sobre el viaje de Ferrière ver Quintino Manuel Junqueira Lopes, «Entre rupturas e continuidades. A Junta de Educação Nacional (1929-36) e a renovação pedagógica e científica liceal», en Aulas abiertas, 74-85; Joan Soler Mata, "La escuela activa de Adolphe Ferrière en la pedagogía española e iberoamericana», en Influencias suizas en la educación española e iberoamericana, ed. José María Hernández Díaz (Salamanca: Ediciones de la Universidad de Salamanca, 2016), 69-82.

23 En 1927 Luzuriaga fue designado miembro del Comité Ejecutivo de la Liga Internacional de la Escuela Nueva y la Revista de Pedagogía, su órgano oficial en España. Ángel Casado Marcos de León, "Filosofía y educación en España. Luzuriaga y la Revista de Pedagogía», BAJO PALABRA. Revista de filosofía 6 (2011): 53-62. 
pedagogía, afirmaba que este tipo de obras eran hasta entonces «adaptaciones o traducciones de obras extranjeras», en referencia a la supuesta procedencia alemana del diccionario de Labor, al que no cita, y advertía sobre su falta de coherencia: "Quizás se diga que hubiera sido deseable la colaboración de diversos pedagogos o especialistas en la redacción de la obra [en referencia la suya]. Pero la experiencia ha demostrado que tal colaboración suele dar un carácter heterogéneo y aún contradictorio a los temas tratados por ellos». ${ }^{24}$

Lo cierto es que, aunque el Diccionario de pedagogía de Labor partía del Lexicon der Pädagogik der Gegenwart de J. Spieler (1930-1932), ${ }^{25}$ se renovó en la edición de 1936 y mantuvo únicamente 40 autores alemanes y austriacos de los 196 del original. ${ }^{26}$ En cualquier caso, no es comparable en extensión con el diccionario de Luzuriaga: 394 páginas, el de Luzuriaga frente a las 1.625, de la de Sánchez Sarto.

La bibliografía ha identificado otras sorprendentes omisiones en la obra de Sarto como el término paidología, cuyo objeto de estudio es el niño y el adolescente. La paidología, que en el momento del publicarse el Diccionario se tenía en alta consideración en la universidad española, fue desarrollada por el pedagogo, político e institucionista Domingo Barnés Salinas. ${ }^{27}$

\section{Las contribuciones editoriales a la internacionalización y renovación de la enseñanza de las ciencias físico-químicas y naturales}

Los planes de estudio del colectivo magisterial incorporaron desde 1911 asignaturas de metodología de enseñanza de la física, química e historia natural. Estas reformas educativas fueron acompañadas por la publicación de manuales prácticos para la enseñanza de estas materias. En Madrid, Publicaciones de la Revista de Pedagogía comenzó a editar

\footnotetext{
24 Luzuriaga, «Prólogo», Diccionario de pedagogía. De esta obra se publicaron al menos tres ediciones, la mencionada en 1960 y posteriormente en 1962 y 1966.

25 Luzuriaga afirma que el antecedente de la obra coordinada por Sánchez Sarto era el diccionario de E. M. Roloff. Lorenzo Luzuriaga, entrada «Bibliografía pedagógica», Diccionario de pedagogía (Buenos Aires: Editorial Losada, 1960), 55.

26 Antón Costa y María Eugenia Bolaño, «El Diccionario de Pedagogía de Labor», 386.

27 José María Hernández Díaz, «Introducción». En Domingo Barnés Salinas, Paidología. Edición de José María Hernández Díaz (Madrid: Biblioteca Nueva, 2008), 1.
} 
en 1924 una colección de pequeños libros, escritos por profesores españoles, de los que aparecieron varias ediciones. Bajo el título Cómo se enseña..., la Serie metodológica publicó obras sobre aritmética y geometría, física y química, ciencias naturales, dibujo, historia y geografía, entre otros. ${ }^{28}$ Estos libritos de menos de 50 páginas ofrecían las reflexiones de cada autor sobre las disciplinas escolares, así como programas para desarrollarlas. Como ejemplo, el volumen de Bargalló contiene un plan de enseñanza en la escuela primaria dedicado «exclusivamente al Maestro" ,29 que debía desarrollar en la extensión que creyera oportuno con la ayuda de algunas lecturas para los niños citadas.

En 1932 la colección Cuadernos de trabajo de la Revista de Pedagogía editó cuatro nuevos títulos sobre metodologías de enseñanza para maestros..$^{30}$ La propia revista difundió en sus páginas la renovación metodológica de las ciencias escolares, como han señalado Damián y Delgado. ${ }^{31}$ También Ediciones de La Lectura (1913-1930) en su sección Ciencia y educación tradujo al español estudios sobre metodología ${ }^{32}$ y editorial La España Moderna (1989-1914) ${ }^{33}$ las obras de grandes pensadores del

${ }_{28}$ Los títulos de la Serie metodológica publicados en 1923 son Cómo se enseña el idioma de Félix Martí Alpera; Cómo se enseñan los trabajos manuales de José Montúa Imbert; Cómo se enseñan las ciencias naturales de Enrique Rioja; Cómo se enseña la historia de Teófilo Sanjuán; Cómo se enseña la geografía de Juan Dantín Cereceda; Cómo se enseñan las ciencias físico-químicas de Modesto Bargalló; Cómo se enseña la aritmética y la geometría de Margarita Comas; Cómo se enseña el dibujo de Víctor Masriera. Posteriormente en 1927 se añadirían Cómo se enseña la economía doméstica de Rosa Sensat y Cómo se enseña el canto y la música de Rafael Benedito. En la Serie escolar cabe mencionar El material de enseñanza (1924) de Vicente Valls y Decoración escolar del profesor normalista Pedro Chico.

29 Bargalló, Como se enseñan las ciencias físico-químicas, 13, nota 1 a pie de página.

30 La colección está formada por Metodología de las ciencias naturales (Vol. I) y Metodología de las ciencias físicas (Vol. IV) del maestro e inspector de primera enseñanza Vicente Valls i Anglés, Metodología de la aritmética y de la geometría (Vol. II) de Margarita Comas y Metodología de la geografía (Vol. III) de Pedro Chico.

31 José Damián López Martínez y María Ángeles Delgado Martínez, «La enseñanza de las ciencias escolares en la Revista de Pedagogía (1922-1936)», Educació i Història: Revista d'Història de l'Educació 24 (juliol-desembre, 2014): 69-101.

32 Entre ellos mencionar la obra de David Gibbs, Ernest Levasseur y Sluys, La enseñanza de la Geografía, 1928, con prólogo, traducción y bibliografía de Ángel do Rego; La enseñanza de la Historia, de Ernest Lavisse, Gabriel Monod, Rafael Altamira y Manuel B. Cossío, 1920, traducida por Domingo Barnés; y La enseñanza de la Gramática, 1922, de Laura Brackenbury, con traducción de Alice Pestana. También dieron a conocer obras de autores españoles, como la de Edmundo Lozano, La enseñanza de las ciencias físico-químicas en 1920.

33 La España Moderna fue creada a imitación de los modelos europeos por el mecenas José Lázaro Galdeano, según Raquel Asún Escartín, «La editorial La España Moderna», Revista de la Facultad de Filología 31-32 (1981-1982): 133-199. 
mundo occidental, entre las que se encontraba La educación y las ciencias naturales de Thomas Huxley, publicada en 1900 y traducida por el doctor Luis Marco.

Entre 1925 y 1937, Editorial Labor editó alrededor de 400 obras de los pedagogos europeos en sus colecciones Biblioteca de Iniciación Cultural y Pedagogía Contemporánea, iniciadas en los años 30, así como de autores españoles, como José Mallart i Cutó, Domingo Barnés y Xoán Vicente Viqueira, que conectaban las innovaciones educativas con las bases de la pedagogía.

Otra de las temáticas de Labor fue la didáctica y la organización escolar, reunidas en la Biblioteca de Pedagogía Contemporánea, sobre la que editó obras en tapa dura con formato libro. En este grupo encontramos el libro del profesor danés Vilhelm Rasmussen, El estudio de la naturaleza en la escuela, publicado en danés en $1909^{34}$ y traducido del inglés al español por Margarita Comas en 1933. Labor publicó ese mismo año la traducción de algunas obras fundamentales de la didáctica del momento, como la de Giuseppe Lombardo-Radice, Lecciones de didáctica, traducida del italiano por Pablo Martínez de Salinas que, al igual que Comas, era profesor de la Escuela Normal de la Generalitat de Cataluña y coautor del Diccionario de pedagogía de Labor.

Labor realizó un esfuerzo por adaptar a los grandes autores europeos al contexto español, como El tesoro del maestro, del pedagogo alemán Adolf Rude, obra en cinco tomos que a lo largo de más de 2.000 páginas reúne las metodologías de enseñanza de las diferentes disciplinas según la Escuela Nueva. Fue traducida y adaptada en 1937 por tres coautores del Diccionario de pedagogía: el inspector de primera enseñanza de Lérida Domingo Tirado Benedí, el maestro nacional de Barcelona Francisco Payarols y el director de la Escuela Nueva Damon de Barcelona Ricardo Crespo. ${ }^{35}$ En concreto, el tomo sobre La enseñanza de las ciencias exactas y naturales fue traducido y adaptado al caso español por Tirado Benedí.

\footnotetext{
34 Vilhelm Rasmussen, El estudio de la naturaleza en la escuela (Barcelona: Editorial Labor, 1933 ), 5.

35 Adolf Rude, El tesoro del maestro, Tomo I: La escuela y sus procedimientos didácticos. Traducción de la cuarta edición alemana por Francisco Payarols y adaptado a la escuela española por Ricardo Crespo (Barcelona: Editorial Labor, 1937); Tomo II: La enseñanza del lenguaje, traducción de Domingo Tirado (Barcelona: Editorial Labor, 1937); Tomo III: La enseñanza de la geografía, enseñanza de la historia y educación cívica, de Franz Schans y Adolf Rude, traducido por Francisco Payarols y la adaptación a la escuela española con numerosos estudios originales por José Junquera Muné
} 
Este conjunto de publicaciones coincidió con el inicio de la edición del gran proyecto de Labor, el Diccionario de pedagogía. Según explicaba el anuncio de la obra, la editorial aspiraba a que se erigiera en una referencia internacional, «en elemento indispensable de orientación y consulta para todos los Profesores, maestros, educadores y estudiantes, así como para aquellas personas que, atentas al desarrollo de la escuela nacional, busquen nuevas sugestiones en las actividades y educadores de los países extranjeros». ${ }^{36}$

No existía hasta el momento una obra de esas características, señalaba una reseña sobre el Diccionario publicada en El Sol. En particular, los maestros de primera enseñanza rurales, explicaba el diario, solicitaban constantemente «libros, informes: piden bibliotecas y pocas veces pueden satisfacer sus deseos». La nueva pedagogía de fuera de España, afirmaba El Sol, iba a remediar esta «necesidad angustiosa de los docentes españoles».37

Una de las causas del atraso de la enseñanza de las ciencias en España se atribuía a la escasa formación científica del colectivo magisterial. El Plan profesional de 1931, instaurado durante la Segunda República, equiparó los estudios de las escuelas normales con los de otras carreras universitarias y ofreció una formación científica adecuada. El trabajo del alumnado, la experimentación y el contacto con la naturaleza, que formaban parte de los principios escolanovistas, se podían poner en práctica en las clases de ciencias y pese a su escasa tradición en el curriculum escolar, comenzaron a apreciarse en España. ${ }^{38}$ Por otro lado, las materias científicas se empezaban a entender como disciplinas transformadoras de la sociedad, lo que las hacía especialmente atractivas. El Diccionario de pedagogía recoge la relevancia que habían adquirido las ciencias físicas y naturales en el programa escolar:

\footnotetext{
(Barcelona: Editorial Labor, 1937); Tomo IV, La enseñanza de las ciencias exactas y naturales, traducción y adaptación española de Domingo Tirado Benedí (Barcelona: Editorial Labor, 1937); Tomo V: La enseñanza del dibujo. La enseñanza de los trabajos manuales. Adaptación a España por Luis Sánchez Sarto. Enseñanza de las Labores femeninas. Adaptación a España por Carmen Sánchez Sarto. Economía doméstica. Gimnasia (Barcelona: Editorial Labor, 1937). Editorial Labor Mexicana reeditó El Tesoro del maestro en 1952.

36 «Diccionario de pedagogía Labor», anuncio en la última página sin numerar del libro de Adolf Rude, La escuela y sus procedimientos didácticos.

37 «El Diccionario de pedagogía», El Sol, 11 de marzo de 1936, 2.

38 Bernal, Renovación pedagógica, 27.
} 
La estructura, totalmente cambiada, del caudal de instrucción de Ciencias naturales condujo, en el trascurso de los últimos treinta años, a una transformación completa de la enseñanza en cuanto a objetivos y métodos [...]. Su propio papel en el programa ha sufrido una evolución radical, pues de ser una materia apenas atendida, ha pasado a ser una de las más importantes en todos los planes modernos y hasta el centro de toda la actividad docente en ciertos sistemas particulares: en el de los centros de interés, por ejemplo. ${ }^{39}$

Cuando llegó la Escuela Nueva a España, la ILE llevaba dos décadas trabajando en propuestas educativas innovadoras para la enseñanza de las ciencias naturales..$^{40}$ La creación del Museo Pedagógico Nacional en 1882 inició la confluencia de las ciencias y la pedagogía. Esta institución se convirtió en un punto de encuentro entre científicos y pedagogos a través de las formaciones prácticas de laboratorio del colectivo magisterial y de instituto, como ha señalado Bernal. ${ }^{41}$ En las secciones de ciencias del Museo y de la Escuela Superior de Magisterio daban clase doctores vinculados al Museo de Ciencias Naturales y la Real Sociedad Española de Historia Natural, como Blas Lázaro Ibiza, Odón de Buen, Edmundo Lozano y Enrique Rioja, que basaban sus enseñanzas en el estudio de la naturaleza con un enfoque ecológico y ambientalista en sustitución de las prácticas tradicionales del coleccionismo y la descripción sistemática. ${ }^{42}$

\section{LA ENSEÑANZA DE LAS CIENCIAS FÍSICO-QUÍMICAS Y NATURALES EN EL DICCIONARIO DE PEDAGOGÍA (1936)}

En este apartado exponemos el análisis de las entradas sobre enseñanza de las ciencias físico-químicas y naturales del Diccionario de pedagogía de 1936: Acuarios, Excursiones, Herbarios, Huerto escolar, Material escolar

\footnotetext{
39 Material escolar, Diccionario de pedagogía, 1993.

40 Del Pozo Andrés, «La Escuela Nueva en España», 321.

41 Bernal, Renovación pedagógica, 38.

42 Bernal, Renovación pedagógica, 106; Cristina Jiménez Artacho, Joaquín Fernández Pérez y José Fonfría Díaz, «Iniciadores en España de la enseñanza ambiental de las ciencias naturales» (comunicación presentada al VIII Congreso de la Sociedad española de Historia de las Ciencias y de las Técnicas, 2002).
} 
(en particular su apartado XI sobre ciencias físicas y naturales), Terrarios, y Enseñanza de las ciencias naturales y Enseñanza de las ciencias físico-químicas que abarcan la escuela primaria, escuelas profesionales y complementarias, escuela secundaria y escuelas normales. ${ }^{43}$

La enseñanza de las ciencias en primaria mereció más espacio que la del resto de niveles educativos, en segundo lugar, las escuelas normales y, finalmente, la enseñanza secundaria, con un pequeño apartado dedicado a las escuelas profesionales. El Diccionario refleja su predilección por los primeros niveles educativos y la formación del colectivo magisterial que compartía con republicanos e institucionistas. ${ }^{44}$

La obra coordinada por Sánchez Sarto mostró asimismo el interés de Labor por las escuelas profesionales. La empresa había editado obras vinculadas a la orientación profesional y las políticas educativas, como la del alemán Georg Kerschensteiner y sus Escuelas de Trabajo. La empresa se mostró favorable al culturalismo pedagógico de la República de Weimar que creía en una educación alejada del intelectualismo y consideraba que el mundo laboral debía estar vinculado a la cultura, la enseñanza profesional y el civismo, según las ideas de Kerschensteiner. ${ }^{45}$

Bajo esta perspectiva, el trabajo constituía una parte esencial de las políticas educativas y las obras vinculadas a la orientación profesional cobraron relevancia en el proyecto editorial de Labor. Los gobiernos de la Segunda República, que sintonizaron con el modelo que proponía la República de Weimar, consideraban las escuelas profesionales parte del

43 Se han asignado abreviaturas a las entradas: Acuarios (ACU), Ciencias físico-químicas, enseñanza de las (EFQ), Ciencias naturales, enseñanza de las (ECN), Excursiones escolares (EXC), Herbarios (HER), Huerto escolar (HUE), Material escolar (ME) y Terrarios (TER).

44 Bernal, Renovación Pedagógica, 106.

45 Según explica el Diccionario de pedagogía en la entrada que le dedica al pedagogo alemán, Labor había publicado la traducción al español de cinco obras de este autor y en 1936 preparaba la edición de dos manuales y dos obras póstumas, de manera que con estas publicaciones podía «considerarse vertida al español toda la obra esencial del eminente pedagogo centroeuropeo». Ver la entrada "Kerschensteiner, Jorge», Diccionario de pedagogía, 1805-1813. La tercera edición de La enseñanza científico-natural fue traducida por Luis Sánchez Sarto en 1930 y publicada por Editorial Labor.

Valbuena afirma que Luzuriaga fue el principal introductor de Kerschensteiner en España. Cecilia Valbuena Canet, «Georg Kerschensteiner y la escuela del trabajo: su introducción en España en el primer tercio del siglo XX a través de la figura de Lorenzo Luzuriaga», Foro de Educación 16, no. 25, (2018): 69-94. 
modelo educativo para la construcción de una nueva ciudadanía y sus valores cívicos, como ha explicado Vilanou Torrano. ${ }^{46}$

\section{El niño científico: la experiencia en la enseñanza de las ciencias físico-químicas}

A continuación, se analiza la entrada sobre enseñanza de las ciencias físico-químicas del Diccionario y se aportan datos sobre la autoría de Margarita Comas. La enseñanza de estas materias científicas debía basarse, según nos explica la entrada, en experiencias en el laboratorio, la naturaleza y visitas a fábricas y talleres, con el fin de que el niño desarrollara destrezas de pensamiento a partir de las cosas que había observado por sí mismo.

Las ciencias se consideraban una de las grandes expresiones históricas del espíritu y servían para "humanizar las mentes de los niños y jóvenes». ${ }^{47}$ El Diccionario reproduce las palabras que escribió en 1925 Margarita Comas en su artículo «Las ciencias en la escuela»: «Las ciencias reclaman un sitio en la escuela únicamente porque representan un movimiento de capital importante en la evolución del espíritu humano, no por su mayor o menos utilidad. Sirven para humanizar las mentes de niños y jóvenes».48

El método científico tenía una función primordial en la enseñanza: «El método científico, es decir, la disciplina mental producida por el estudio de las ciencias es, en general, lo importante». ${ }^{49}$ La entrada del Diccionario continúa su argumentación sobre esta metodología exponiendo que la adquisición de hábitos intelectuales debía ir acompañada de instrucción y conocimientos, según las teorías de Kerschensteiner en La enseñanza científico-natural. Efectivamente, en este libro el pedagogo alemán manifiesta «el extraordinario valor de las Ciencias naturales para la instrucción formal $»^{50}$ y se muestra partidario de los estudios de Theodre H. Huxley y

\footnotetext{
46 Vilanou Torrano. «Joaquín Roura Parella», 187.

47 EFQ, 569.

48 Margarita Comas, «Las ciencias en la escuela», Revista de Pedagogía 38 (1925): 57.

49 EFQ, 569.

50 Kerschensteiner, La enseñanza científico-natural, 9.
} 
John Dewey sobre los procesos del pensamiento. ${ }^{51}$ En España, Edmundo Lozano, profesor de la ILE, destacó por su defensa del uso del método científico para la adquisición del hábito científico en lugar de la mera adquisición de conocimientos. ${ }^{52}$ Su obra La Química en la escuela primaria, publicada en Madrid en 1913, se cita en el Diccionario.

En lugar de que fuera el profesor quien realizara experimentos espectaculares, era preferible que el alumnado los planteara de manera rudimentaria para que con la práctica aprendiera por sí mismo a resolver problemas. Según explica la entrada, la enseñanza de las ciencias del sistema educativo inglés lograba hacer confluir el aprendizaje práctico y el desarrollo de la capacidad de pensar mediante las experiencias en el laboratorio, las explicaciones y los experimentos prácticos relacionados con la vida cotidiana. Esta metodología de enseñanza del sistema inglés la había expuesto Margarita Comas en su artículo «La enseñanza elemental de las ciencias en Inglaterra $»^{53}$ y la retoma en el siguiente párrafo del Diccionario:

Esto es lo que en Inglaterra llaman problem method: no hay clase propiamente dicha; los alumnos trabajan en el laboratorio y el maestro no hace más que sugerir caminos e indicar algún error de método. Empleado exclusivamente, tiene este sistema la desventaja de limitar de un modo excesivo el campo de la materia, de restringir la visión, y quizá, por ello mismo, de matar a la larga el interés: pero combinándolo con lecturas, conferencias, visitas a fábricas y talleres, etc. da excelentes resultados. ${ }^{54}$

Otro método de enseñanza planteado en la entrada proponía situar al estudiante en el lugar del hombre de ciencia, lo que le facilitaría el desarrollo de su capacidad de raciocinio y curiosidad innata.

Esta importancia concedida al método hace que el ideal de la enseñanza sea colocar a los estudiantes en la misma posición de

\footnotetext{
51 Kerschensteiner, La enseñanza científico-natural, 7.

52 Bernal, Renovación pedagógica, 94.

53 Margarita Comas, "La enseñanza elemental de las ciencias en Inglaterra», Boletín de Institución Libre de Enseñanza 46 (1922), 83.

54 EFQ, 571.
} 
espíritu que es peculiar en el hombre de ciencia, no para que descubran por sí mismos, en unos pocos años, lo que ha requerido siglos de la vida de la Humanidad para ser descubierto, sino que al mirar como él por sus propios ojos y manejar sus instrumentos, adquieran y puedan aplicar a las demás cosas de la vida las cualidades de observación, raciocinio, etc. propias del investigador que halla nuevos enigmas [...] y experimenten [...] algo de su alegre sentido de intelectual aventura. ${ }^{55}$

La idea de permitir al niño realizar experiencias sencillas por sí mismo y que se pusiera en la piel del sabio la apuntaba ya Rasmussen en 1909: "Cada alumno ha de convertirse en un naturalista en miniatura o, si se quiere de otro modo, en un investigador científico», sostenía el profesor danés. ${ }^{56}$

Según Bernal, ${ }^{57}$ Margarita Comas propuso por primera vez en España la posibilidad de que el niño se pusiera en lugar del sabio, una novedad respecto a otros autores, como Lozano, Rioja o Vicente Valls. Bargalló estaba alejado de esta idea de Comas vertida en el Diccionario: en 1925 el profesor normalista recomendaba que los temas de los primeros cursos de la escuela primaria formaran parte «de las lecciones cosas sobre seres o utensilios vulgares. La enseñanza será casi exclusivamente descriptiva y oral; podrá ilustrarse en algunos momentos con lecturas dadas principalmente por el Maestro».58

La entrada del Diccionario considera, asimismo, que la selección de los contenidos debía estar orientada al conocimiento del entorno natural del estudiante. Por eso, en las escuelas rurales convenía posponer hasta el último curso de primaria la enseñanza de las ciencias físico-químicas y sustituirlas por el estudio de la naturaleza. En la ciudad había más facilidades para visitar fábricas y talleres, de manera que la formación científica podía centrarse en las ciencias físico-químicas.

\footnotetext{
55 EFQ, 570. Este párrafo del Diccionario aparece en Comas, «La enseñanza elemental de las ciencias en Inglaterra», 82.

56 Rasmussen, El estudio de la naturaleza, 5.

57 Bernal, Renovación pedagógica, 1.

58 Bargalló, Cómo se enseñan las ciencias físico-químicas, 11.
} 
Ante todo, la enseñanza de las ciencias físico-químicas debía basarse en la experimentación. El Diccionario relata un experimento planteado por John Dewey en su obra How we think, publicada en 1910. Dewey, pedagogo de referencia de Comas, ${ }^{59}$ desarrolló el concepto de indagación y experiencia; pensaba que la enseñanza de las ciencias debía desarrollar las habilidades para hacer ciencia, relegando en segundo plano la acumulación de información. Establecía como punto de partida la experiencia del niño, la detección de un problema, la emisión de hipótesis y su puesta a prueba, todo ello dentro de su capacidad intelectual, de manera que pudiera encontrar modos de resolverlo por sí mismo. La ILE publicó las primeras informaciones sobre la pedagogía norteamericana, en concreto sobre Dewey y su escuela experimental de la Universidad de Chicago. ${ }^{60}$

En la entrada del Diccionario se priorizan la sencillez de los espacios y la economía de los materiales en el aula de ciencias: un laboratorio sencillo o, mejor, una sala para trabajos manuales, e instrumentos que no resulten costosos en tiempo y dinero fabricar en el caso de la escuela primaria, utilizando siempre que fuera posible objetos de la vida cotidiana.

La austeridad no estaba reñida con el rigor del estudio en la clase de ciencias. El Diccionario rechaza «la tendencia a convertir la enseñanza de las ciencias en un simple pretexto para la clase de trabajos manuales» y considera que debe atender a un plan. Este argumento coincide con el de Herbert Spencer ${ }^{61}$ que consideraba los trabajos manuales una buena idea, pero mal aplicada.

En cuanto al trabajo del estudiante, eran imprescindibles el dibujo, los esquemas y las redacciones, así como el cuaderno de trabajo para anotar observaciones y razonamientos, y dibujar gráficas. Se recomienda limitar los contenidos en favor de la profundidad de su tratamiento: «Pocos asuntos pero que apasionen [...] tratados todo lo a fondo que permita la inteligencia de los alumnos». ${ }^{62}$ Los libros de texto eran

\footnotetext{
59 Bernal, Renovación pedagógica, 38.

60 Del Pozo Andrés, «La Escuela Nueva en España», 321.

61 Herbert Spencer, Ensayos sobre Pedagogía (Madrid: Akal, 1983), 94.

62 EFQ, 573.
} 
prescindibles, si bien se recomendaba contar con buenos manuales, monografías y biografías como materiales de consulta.

La formación del colectivo magisterial debía estar formada por una parte de cultura general y otra de metodología de enseñanza que incluyera el «ver hacer y hacer uno mismo». El Diccionario considera que todos los docentes, maestros y profesores de secundaria, precisaban de formación pedagógica: "Ya hoy van comprendiendo en casi todos los países que no basta saber una cosa para poderla enseñar bien, y por eso va siendo obligatorio el certificado pedagógico para aspirar a la cátedra de Instituto».63

Del mismo modo, los capítulos esenciales de la historia de la ciencia, los primeros pasos dados por los científicos en el pasado, podían ayudar a los jóvenes alumnos a comprender los descubrimientos más recientes. Esta era una de las metodologías de enseñanza que defendió Modesto Bargalló.

\section{Aprender a pensar con la naturaleza: hábitos, valores y pensamiento racional en la enseñanza de las ciencias naturales}

Rafael Candel Vila pudo ser el autor anónimo de la entrada sobre enseñanza de las ciencias naturales. Analizamos sus contenidos, relacionándolos con las ideas pedagógicas y la trayectoria de este científico, así como los referentes a las entradas acuarios, excursiones, huerto escolar, material escolar y terrarios.

Los principales valores formativos y la utilidad de las ciencias naturales en la escuela, según el Diccionario, residían en su capacidad para fomentar el pensamiento crítico, buenos hábitos, el autoconocimiento y los valores cívicos de convivencia:

[La enseñanza de las ciencias naturales] posee valores educativos propios: [...] nos enseña a considerar rectamente nuestra propia vida, valorándola y dirigiéndola de un modo natural y consciente, nos muestra como los problemas científico-naturales [...] hacen fructificar $[\ldots]$ la conciencia cívica. Quien llega a conocer los

63 EFQ, 576. 
problemas de la Ciencia natural y aprende a pensar de acuerdo con la Naturaleza puede [...] formar una opinión propia bien cimentada, sin dejarse cegar por sugestiones faltas de sentido. ${ }^{64}$

La entrada sobre enseñanza de las ciencias naturales hace reiteradas referencias al respeto, admiración y conservación de la naturaleza. El coautor propone «cultivar el goce de la naturaleza, el amor ante los objetos naturales mediante el reconocimiento, comprensión y valoración de la Naturaleza». ${ }^{65}$ De esta forma, entre las materias científicas a tratar en el aula incluye, junto a la geobotánica, la sociología de las plantas y las teorías de las especies y de la herencia, «la conservación de la Naturaleza y de los monumentos naturales». ${ }^{66}$ La convicción de que el estudio de las ciencias estimulaba estos vínculos afectivos aparece de manera constante en la obra de Rasmussen El estudio de la naturaleza en la escuela, citado en la entrada: "las ciencias naturales [...] proporcionan una base experimental al amor a la Naturaleza». ${ }^{67}$

El coautor de la entrada sobre enseñanza de las ciencias naturales otorga el mismo rango a la mineralogía que a la biología, la física y la química, y menciona los estudios sobre minerales y rocas, y al explorador científico Alexandre v. Humboldt, lo que nos remite a la especialidad científica de Candel que destacó como investigador en mineralogía, cristalografía y geoquímica, y era experto en expediciones científicas.

Una adecuada selección del material de enseñanza podía facilitar la relación entre el estudiante y los seres vivos, y captar su atención. Las excursiones, los acuarios y los terrarios ofrecían valiosas experiencias fuera y dentro del aula, y el huerto constituía un instrumento eficaz para la observación directa de la naturaleza en las escuelas de las ciudades.

La entrada sobre huertos pone como ejemplo de buenas prácticas la Sociedad de huertos escolares, fundada en Zurich en 1911, y los creados en las escuelas alemanas tras la gran Guerra. Según la entrada, en estos países los huertos estaban a medio camino entre los jardines botánicos

\footnotetext{
64 ECN, 580.

65 ECN, 579.

66 ECN, 579.

67 Rasmussen, El estudio de la naturaleza, 255.
} 
y los huertos de trabajo, según las consignas del movimiento de la escuela de trabajo. El huerto escolar debía ser instrumento de la enseñanza libre y la instrucción activa y facilitar los estudios biológicos y económicos de los vegetales: 68

La escuela nueva mantiene que el valor intuitivo e instructivo del material de enseñanza es tanto mayor cuanto más se aproxima a la realidad natural y a la vida, y que, por consiguiente, la naturaleza viva debe ocupar el primer plano, observándola en las excursiones escolares, o bien en los jardines de la escuela y en los acuarios y terrarios que se tengan en clase o que se visiten periódicamente. ${ }^{69}$

Las entradas sobre acuarios y terrarios ofrecen amplia información sobre su utilidad, contenidos que pueden tratarse a partir de ellos, así como instrucciones para su montaje y mantenimiento en un aula. Los acuarios mostraban al observador atento «las relaciones de intercambio entre los individuos y las condiciones de vida de la pequeña comunidad en aquel "mar en un vaso de agua» y ofrecían materiales de interés inagotables para los estudios variadísimos, morfológicos, anatómicos, fisiológicos y ecológicos».70 Se recomendaba usar acuarios y terrarios que no necesitaran instalaciones costosas de calefacción, bien en el aula con especies locales de animales y plantas de agua salada, tales como «equinodermos, erizos de mar, y asterias; celenterados, ciertos antozoos y esponjas», ${ }^{71} \mathrm{o}$ de mayores dimensiones al aire libre en el jardín escolar.

En la entrada Acuarios se citan dos obras publicadas en 1933 por Labor en su Biblioteca de Pedagogía Contemporánea, traducidas por Margarita Comas y Pablo Martínez de Salinas, respectivamente, ambos coautores del Diccionario de pedagogía y profesores en aquel momento de la Escuela Normal de la Generalitat de Cataluña: El estudio de la naturaleza en la escuela de Rasmussen, donde el profesor danés explicaba la forma de organizar un acuario en el aula y las especies que debía contener, y Lecciones de didáctica de G. Lombardo-Radice, que dedica un

\footnotetext{
68 HUE, 1617-1618.

$69 \mathrm{ECN}, 581$.

70 ACU, 19.

71 ACU, 19.
} 
capítulo a la enseñanza de las ciencias. El Diccionario de pedagogía no contempla el museo escolar o los animales disecados, elementos que eran habituales en el aula de ciencias de la época. Lo fundamental era aprender del ser vivo.

En cuanto a los herbarios, facilitaban al alumnado conocer las distintas morfologías de hojas y flores, así como las adaptaciones y tipos de plantas. La entrada distingue entre el herbario sistemático de los botánicos profesionales y el biológico, recomendado este último en educación por poder reutilizarse,$^{72}$ teniendo el maestro precaución sobre la pasión coleccionista de los escolares que «acaban por exterminar todas las especies raras e interesantes de la localidad». ${ }^{73}$

A finales del siglo XIX, el botánico Blas Lázaro Ibiza ya alertaba sobre la afición recolectora del alumnado y la destrucción de la flora autóctona. ${ }^{74}$ También Enrique Rioja, ${ }^{75}$ cuya obra Cómo se enseñan las ciencias naturales se cita en la entrada, rechazaba el coleccionismo sin una función educadora y planteaba en su lugar el estudio de los seres vivos con un enfoque ecológico que permitiera conocer sus relaciones. En esta misma fecha Margarita Comas afirmaba que «el Museo no tiene valor más que cuando es una cosa viva» y exponía la forma de montar un acuario y un terrario, su utilidad y las especies que podía contener. Prevenía también sobre «el afán coleccionador que les impulsa [a los niños] a recoger $[\ldots]$ insectos o plantas si se les ha impulsado por este camino». ${ }^{76}$

En sus años republicanos en Barcelona, cuando se inició el Diccionario de Labor, Candel Vila desarrolló su faceta pedagógica como profesor de secundaria del Institut-Escola Ausias March de Barcelona, donde comenzó a trabajar en 1933 y llegó a ser director en 1935. ${ }^{77}$ Como secretario general de la Junta de Ciencies Naturals de Cataluña se implicó en la

\footnotetext{
72 HER, 1554.

73 HER, 1555.

74 Bernal, Renovación pedagógica, 112.

75 La primera edición se publicó en 1925. Rioja, Cómo se enseñan las ciencias naturales, 24 (cuarta edición, 1931).

76 Margarita Comas. «Las ciencias en la escuela», Revista de Pedagogía 38 (1925): 56-64.

77 Al finalizar la guerra civil, Candel Vila se vio obligado a exiliarse a Francia en unas condiciones económicas precarias y sin su familia. Volvió a España en 1948. En los primeros meses tras su vuelta, siguió colaborando con Editorial Labor, según explica Manuel Font i Aldaba en su necrológica.
} 
enseñanza y divulgación de las ciencias naturales, pronunció conferencias y publicó artículos sobre experiencias de la escuela activa para la enseñanza de las ciencias en la naturaleza en el Butlletí del Institut escola y el Butlletí de Mestres. ${ }^{78}$

El Institut-Escola contribuyó a la aplicación de los principios de la Escuela Nueva a la enseñanza media en Cataluña ${ }^{79}$ que, como veremos a continuación, plasmó Candel en el Diccionario de pedagogía: el trabajo por proyectos, la educación laica e integral, la enseñanza de los idiomas, la educación emocional y en valores, la sustitución del libro de texto por los cuadernos de clase elaborados por el propio alumnado a partir de sus apuntes, las composiciones escritas y una concepción de la educación en la que el estudiante constituye el centro del proceso de enseñanza-aprendizaje y el profesor un guía. Nos gustaría destacar la relevancia que la entrada sobre enseñanza de las ciencias naturales otorga a las salidas al campo y a las excursiones para aprender geografía y ciencias naturales de España. ${ }^{80}$ Las excursiones formaron parte del programa pedagógico del Institut-Escola y Candel Vila, como profesor, participó activamente organizándolas de manera continuada a lo largo de su carrera docente. ${ }^{81}$

Los gobiernos de la Segunda República veían en las excursiones un valioso elemento de cultura y educación y las potenciaron: «Un excursionismo escolar bien entendido es un pedazo de la escuela de la vida y un contrapeso a la escuela del libro, que favorece la autonomía del alumnado y su sentido del descubrimiento». ${ }^{82}$ Como reacción ante el intelectualismo y el formalismo, se plantea la acción educativa a través de las

\footnotetext{
Manuel Font i Aldaba, «Rafael Candel Vila. Necrológica», 1979. Ver también López-Ocón, Aulas Abiertas, 443-454.

78 Según López-Ocón, como resultado de estas experiencias, Candel publicó «Algunes observaciones sobre l'ensenyament de la historia natural», «Observacions d'història natural durant les vacances», "Les ciències de la naturalessa i les realitats de la ecola activa», «Importància del museus escolars i comarcals» mayoritarimente en el Butlletí de l'Institut-Escola. López-Ocón, «La trayectoria de 55 docentes», 448.

79 María Inmaculada Rius Dalmau, Institut-Escola de Barcelona (1931-1939), Grup de Reçerca en Lingüística aplicada, Universitat Rovira I Virgili, http://www.grelinap.recerca.urv.cat/ca/projectes/diccionario-historia-ensenanza-frances-espana/entradas/111/institut-escola-de-barcelona-1931-1939.

80 EXC, 1362.

81 Sobre las excursiones organizadas por Candel Vila, ver López-Ocón, «La trayectoria de 55 docentes», 448.

82 EXC, 1361.
} 
excursiones en la naturaleza que permitían el desarrollo de la capacidad de observación y de la razón a través del método científico y que, como ha señalado Guijarro, promovía la nueva pedagogía junto a los objetos y los ambientes recreativos. ${ }^{83}$

Las excursiones influían sobre la salud y la autoestima del estudiante:

Investigaciones anatómico-fisiológicas demuestran la acción benéfica del excursionismo sobre el corazón y los pulmones, sobre la circulación sanguínea y el sistema nervioso. La excursión contribuye a fortalecer el cuerpo, a formar el espíritu y a enriquecer el alma, a cuidar y probar las virtudes sociales y políticas de la comunidad, el mutuo respeto y la propia defensa, [...] a engendrar en la juventud el sentido de los valores de la patria y la nacionalidad y procurarle, por último, los goces de la Naturaleza [...]. ${ }^{84}$

La cita finaliza afirmando que «El excursionismo adquiere más importancia ante la atrofia con que se ven amenazadas las fuerzas y aptitudes vitales en los niños de las grandes urbes a consecuencia de su aislamiento de la naturaleza». 85

Para enseñar ciencias naturales, el maestro debía desarrollar tareas con sus estudiantes mediante «un libre cambio de impresiones sobre el objeto de estudio y una enseñanza que tienda a la participación y a la asociación de trabajos». ${ }^{86}$ Se proponía la realización de trabajos individuales o colectivos en casa por parte de los estudiantes: "Las observaciones fenomenológicas que exigen el trazado de tablas (variación de la temperatura, llegada y partida de las aves de paso, floración de las plantas, etc.) son muy adecuadas para que el niño permanezca atento a la Naturaleza y para fomentar la reflexión sobre los fenómenos naturales». ${ }^{87}$

\footnotetext{
83 Guijarro, Artefactos y acción educativa, 218.

84 EXC, 1350-1360.

85 EXC, 1360. Esta idea está vigente en la actualidad. Richar Louv acuñó en su libro Last child in the Woods publicado en 2005 el término Natural Deficit Disorder que, según el autor, padecen los niños y niñas de las sociedades industrializadas actuales como consecuencia de su alejamiento de la naturaleza. En 2018 se publicó la traducción al español de la obra. Richard Louv, Los últimos niños en el bosque, (Madrid: Capitán Swing, 2018).

86 ECN, 582.

87 ECN, 583.
} 
Partiendo del objeto natural como centro de la actividad de la clase, el estudiante aprendía valores y conocimientos, así como destrezas y habilidades. Los acuarios y terrarios del aula permitían desarrollar hábitos de trabajo si estaban a cargo de los alumnos mismos.

El desarrollo recto de la lección está garantizado por la adecuada colaboración de maestro y alumnos y por un libre cambio de impresiones sobre el objeto de estudio y una enseñanza que tiende a la participación y a la asociación en los trabajos. Como centro de actividad aparece el objeto natural; los alumnos observan, juzgan, informan, comparan y aplican cuando plantean preguntas y se organiza la enseñanza en plena libertad. 88

El coautor de la entrada es partidario de la integración de los contenidos de ciencias con los del resto del programa escolar de las escuelas primarias y secundarias, atendiendo a «todos los valores instructivos (intelectuales, estéticos, artísticos, éticos, higiénicos y económicos)».89 En enseñanza primaria considera que:

No deben desarrollarse sectores científicos aislados sin guardar una debida conexión con los restantes conocimientos, si bien se tenderá a una cierta concentración de las materias de enseñanza: el asunto a estudiar de Química, Física y Mineralogía podrá encajarse en el conjunto presidido por la unidad vital (colectividad de vida y cultura) de igual modo que se hace con la Biología..$^{90}$

Como indicaba la Escuela Nueva, la enseñanza de las ciencias debía ser activa y atender a la psicología del niño y sus necesidades en las diferentes etapas de desarrollo. En enseñanza primaria el maestro debía ser flexible y acomodar la clase a sus jóvenes alumnos: «Una interrogación [...] puede servir de punto de partida para una enseñanza animada y $[\ldots]$ puede motivar una lección, aunque cuando no estuviese prevista; el plan no debe ser excesivamente rígido». ${ }^{91}$ Durante los dos primeros cursos de este ciclo educativo el método debía ser intuitivo: «la materia

\footnotetext{
$88 \mathrm{ECN}, 582$.

89 ECN, 581.

90 ECN, 583.

91 ECN, 584.
} 
de enseñanza debe estar reducida a un conjunto globalizado y a las lecciones de cosas que rodean al niño. En tercero y cuarto se atiende más a la región en que el alumnado vive [...] Todavía no se da una enseñanza científico natural propiamente dicha».92

En los primeros años de escuela, la secuenciación de los programas debía ser cíclica, creciente en dificultad y el método concéntrico, de manera que se integraran los contenidos de la enseñanza. En los últimos cursos escolares, se proponía que «los fines se determinen desde un punto de vista económico, con especial atención a las necesidades de la vida». ${ }^{93}$ En estos párrafos el coautor de la entrada comparte las ideas del pedagogo católico Rufino Blanco, cuya obra Ensayo de un programa cíclico y concéntrico de ciencias naturales (Madrid, 1904) cita en la bibliografía al final de la entrada.

En las escuelas secundarias la entrada del Diccionario plantea la conexión de las materias de enseñanza, por ejemplo, la física, la química y las lenguas extranjeras, a través de la lectura de estudios y relatos de investigadores, exploradores y descubrimientos.

En cuanto a la formación científica del colectivo magisterial, debía ser completa y dividida en dos etapas: una formación cultural y otra dirigida a la práctica profesional en la escuela. El cuerpo de conocimientos integraría el de los seres vivos y las leyes biológicas fundamentales, adquiridos siempre a través de una formación práctica, el dominio de una serie de técnicas de trabajo con rocas y minerales, microscopio, uso de claves de identificación de seres vivos, así como excursiones y paseos, visitas a museos de ciencias naturales, botánicos y zoológicos, etc.

Para iniciarse en la práctica escolar el estudiante de magisterio debía conocer las metodologías de enseñanza de las ciencias y sus peculiaridades respecto al aprendizaje de otras materias, así como los medios para su enseñanza, que incluían la elaboración de acuarios, insectarios, proyecciones, láminas... El aprendizaje se debía completar con la preparación de programas y lecciones, estudio de libros de lectura, y prácticas escolares en centros próximos.

\footnotetext{
92 ECN, 582.

93 ECN, 582.
} 
El coautor hace referencia en la bibliografía a la obra de dos profesoras republicanas ${ }^{94}$ que habían sido becadas por la JAE para aprender metodologías docentes fuera de España: Margarita Comas ${ }^{95}$ y Dolores Cebrián y Fernández de Villegas. ${ }^{96}$ La entrada cita el artículo de Comas, «La enseñanza elemental de las ciencias en Inglaterra», uno de los referentes del profesorado de ciencias español. ${ }^{97}$ El Diccionario menciona también al folleto de Cebrián, Métodos y prácticas para la enseñanza de las Ciencias naturales, publicado en Madrid en 1914, en el que daba cuenta de las metodologías de enseñanza de las ciencias naturales de la escuelas francesas e inglesas.

El estudio de la naturaleza o Nature study es el principal referente de la entrada sobre enseñanza de las ciencias naturales del Diccionario. Este movimiento proponía las salidas al campo y la construcción de artefactos para mantener seres vivos en el aula a partir de objetos de la vida cotidiana, actividades estimulantes y formativas opuestas a las prácticas pedagógicas tradicionales magistrocéntricas y el uso del libro de texto. ${ }^{98}$ Según el Nature study, la enseñanza de las ciencias debía partir de la observación de los seres vivos en su medio, el estudio ecológico y ambientalista, y el respeto y la admiración por la naturaleza.

Otro de los referentes del coautor de la entrada sobre la enseñanza de las ciencias naturales es la citada obra de Rasmussen, El estudio de la naturaleza en la escuela, que aparece en el cuerpo del texto y también en la bibliografía. En 1909 ya proponía el profesor danés huir de la

\footnotetext{
$94 \mathrm{Al}$ iniciarse la guerra civil, Margarita Comas tuvo que exiliarse a Inglaterra y Dolores Cebrián fue depurada y no pudo volver a ejercer la enseñanza.

${ }_{95}$ En 1921 Margarita Comas recibió en una beca de la JAE para asistir como alumna al London Day Trainning Collage de la Universidad de Londres. Durante la estancia, Comas también tuvo ocasión de acudir a sesiones en el Bedford College for Women, primer centro de investigación para mujeres creado en Inglaterra que desde 1900 formaba parte de la Universidad de Londres y gozaba de gran reputación, y en el University College. También se matriculó en el King's College para aprender zoología y en el Sir John Cass Institute para Física y Química. Delgado, Margarita Comas, científica y pedagoga, 68-70.

96 Dolores Cebrián (1881-1973), maestra y profesora de ciencias de las Escuelas Normales, recibió una ayuda de la JAE para visitar la sección de Pedagogía de la Exposición franco-británica de Londres celebrada en 1908. Posteriormente fue becada para estudiar botánica en Francia y Alemania. De vuelta a España su preparación en esta disciplina le permitió ser agregada al Museo de Ciencias Naturales.

97 Bernal, Renovación pedagógica, 133.

98 Sally G. Kohlstedt, «Nature, not Books. Scientist and the Origin of Nature-Study movement in the 1890's», Isis 96 (2005): 324-352; Sally G. Kohlstedt, Teaching Children Science: Hand-on Nature Study in North America, 1890-1930 (Chicago: University of Chicago Press, 2010).
} 
sistemática, permitir la experiencia directa y la observación de los fenómenos naturales, y atender a las necesidades estéticas de los alumnos y su interés por las manifestaciones de la vida. El dibujo, el cuaderno del alumno, el calendario de la naturaleza - que permitía registrar los cambios que se producían con las estaciones y estimulaba la capacidad de observación del estudiante-,99 las redacciones y la conversación eran recursos y métodos de trabajo de Rasmussen que recoge el Diccionario de pedagogía. ${ }^{100}$ Siguiendo al danés, afirma la entrada del Diccionario que «Las composiciones escritas de pequeño alcance son muy adecuadas para despertar el amor a los procesos naturales, y los dibujos son un poderoso acicate para la observación exacta y minuciosa».101

La entrada sobre enseñanza de las ciencias naturales muestra como las ideas renovadoras conviven con algunas propias de la educación tradicional, lo que nos remite a las reflexiones de Del Pozo sobre los limitados resultados de la aplicación de la Escuela Nueva en España. ${ }^{102}$ Aparecen elementos del modelo de enseñanza dogmático-demostrativo, que perseguía proporcionar una cultura general a un sector minoritario, y otro de carácter integral-constructivo, que contemplaba el aprendizaje en las primeras etapas, atendía a la participación del estudiante y a la educación práctica, así como a su formación física e intelectual, según la clasificación de Guijarro. ${ }^{103}$

En coeducación, por un lado, el coautor de la entrada se muestra conservador: consideraba que niños y niñas debían aprender contenidos diferentes, reservando a estas últimas su tradicional función de cuidadoras en las escuelas primarias: «Las niñas deberían tratar las cuestiones referentes al cuidado de los enfermos y niños pequeños», afirma. En las secundarias también se consideraba vital atender a la «diversidad de los sexos», aunque no especifica cómo. ${ }^{104}$

\footnotetext{
99 Rasmussen, El estudio de la naturaleza, 200-201.

100 Rasmussen, El estudio de la naturaleza, 167.

101 ECN, 584.

102 Del Pozo Andrés, «La Escuela Nueva en España», 321.

103 Guijarro, Artefactos y acción educativa, 37.

104 ECN, 582.
} 
Por otro, hace una curiosa propuesta de educación sexual que procede de la citada obra de Rasmussen:

Los maestros, cada vez más numerosos, que creen necesaria una educación sexual de sus alumnos, tienen en la enseñanza de la Biología la base adecuada para ello, partiendo del estudio de la reproducción de las plantas para llegar paulatinamente al de los animales superiores; muchas veces no hay necesidad de plantearse el problema humano [de la sexualidad], pues queda resuelto por analogía, sin dificultad ni embarazo, incluso en el caso de las escuelas mixtas. ${ }^{105}$

Efectivamente, el profesor danés afirmaba en su obra haber abordado con naturalidad estos temas con sus alumnos y alumnas de 10 a 15 años en la clase de ciencias: «el terreno sexual es [...] mucho menos misterioso para los niños de lo que se cree generalmente». ${ }^{106}$ Para demostrarlo recoge el testimonio de una de sus estudiantes: «mediante la Biología he aprendido a considerar con naturalidad todas las cosas que ocurren en la Naturaleza; me refiero, sobre todo, a lo que muchas gentes desean siempre comentar en voz baja [...], a saber: el primer desenvolvimiento del ser humano», ${ }^{107}$ en referencia a la fecundación.

Para finalizar, la entrada sobre material escolar, que incluye un apartado para la enseñanza de las ciencias, afirma que «la pedagogía moderna cree que la realidad es el primero y más importante manantial de conocimiento" ${ }^{108}$ según las ideas de la ILE. No obstante, se había multiplicado, perfeccionado y estandarizado la fabricación de los materiales escolares, como los aparatos desmontables y los elementos de construcción, para la enseñanza de las ciencias, con importancia creciente en la escuela. ${ }^{109}$ Si bien en España estaba poco desarrollada la fabricación de

\footnotetext{
105 ECN, 582.

106 Rasmussen, El estudio de la naturaleza, 169.

107 Rasmussen, El estudio de la naturaleza, 170.

108 ME, 1987.

109 Gabriela Mayoni ha mostrado como, a finales del siglo XIX, se incrementó y diversificó la oferta de las empresas que fabricaban materiales científicos que se expandieron por todo el mundo y en particular en los colegios argentinos. María-Gabriela Mayoni, «Dispositivos para la enseñanza de la naturaleza. Tecnología y modernidad en los colegios argentinos de finales del siglo XIX», Historia y sociedad 40 (enero-junio, 2021): 171-197.
} 
material científico para enseñanza primaria, la entrada remite a la obra publicada por algunos profesores y maestros sobre el tema, sin precisar a quién se refiere ni ofrecer referencias bibliográficas.

El Diccionario se muestra partidario de una enseñanza activa que promueva la indagación y el trabajo del alumnado: «La enseñanza de la física y química no puede concebirse ya bajo otras formas que las propias de la escuela activa, con ejercicios y experimentos escolares, de forma que junto al aparato demostrativo debía aparecer «el aparato de trabajo para el alumno». En estas disciplinas «Los elementos reales han sido puestos al servicio de la enseñanza bajo diversas formas de preparados líquidos y secos».110

En biología, se propone el uso de láminas y colecciones de estampas representando minerales, vegetales, animales y órganos del cuerpo, "modelos plásticos, duraderos, desmontables y exactos, utilísimos para la enseñanza de la Anatomía, Zoología y Botánica. Las láminas y colecciones de estampas representando minerales, vegetales y animales se producen en número incalculable, facilitándolas el comercio [...]».111

Recursos como las láminas, que representaban de manera visual la naturaleza y se exponían en las aulas, complementaban el excursionismo y se hicieron muy populares entre 1870 y 1920 debido a los avances de las tecnologías de impresión. ${ }^{112}$

\section{REFLEXIONES FINALES}

Las editoriales de Madrid y Barcelona contribuyeron a la internacionalización de la pedagogía española y formaron parte del proyecto para impulsar el cambio metodológico en la enseñanza de las materias científicas en torno a 1925-1936. Sus propuestas renovadoras iban a acompañar a los

\footnotetext{
$110 \quad$ ME, 1993.

111 ME, 1993.

112 José Pedro Marín, «Categorización de los materiales didácticos», 6. Santiago Aragón, Carmen López y Francisco Javier Frutos, "La enseñanza a través de las imágenes del Instituto-Escuela», Ciencia e innovación en las aulas, 142. Ver también Francisco Frutos, Carmen López-San Segundo, Beatriz González de Garay Domínguez y Manuela García, «La linterna de proyección y la renovación de la educación científica de los bachilleres españoles en el primer tercio del siglo XX», Aulas abiertas, 219-252.
} 
nuevos planes de estudios de formación del magisterio, colectivo que los gobiernos de la Segunda República consideraban clave para la formación de una nueva ciudadanía y la modernización del país.

El gran proyecto de Editorial Labor, el Diccionario de pedagogía de 1936, supuso un esfuerzo para traer a España las propuestas internacionales para este cambio educativo. Reunió los contenidos, el valor formativo y las prácticas profesionales de la enseñanza de las ciencias y ofreció a los docentes experiencias, métodos y recursos que venían desarrollando autores españoles, como Lozano, Rioja, Bargalló y Comas, y extranjeros, como Dewey, Kerschensteiner, Lombardo-Radice y Rasmussen.

Las propuestas del Diccionario partieron de los principios básicos de la Escuela Nueva: el niño como centro de la educación, el profesor como guía y la educación integral del alumno. La obra nos presenta un aula de ciencias democrática en la que la enseñanza se sustenta en el diálogo, la experiencia, el estímulo de la curiosidad y el trabajo individual y colectivo de los estudiantes.

El respeto y amor por la naturaleza y la admiración por lo vivo se ofrecen como valores asociados a la enseñanza de la ciencia. Las disciplinas científicas adquieren relevancia por su capacidad para transformar al individuo desde los primeros niveles educativos y facilitar el pensamiento crítico, así como la conciencia cívica y ciudadana que formaba parte del programa reformador de los republicanos. De esta manera, el estudio del ser vivo se convertía en el centro del aula de ciencias, bien en acuarios, herbarios, huerto escolar y terrarios, bien en las salidas fuera del aula.

En el conjunto de principios, ideas y prácticas de la enseñanza de las materias científicas en el Diccionario aparecen elementos del programa pedagógico de la ILE, de la Escuela Nueva y de la escuela tradicional española. Convive un modelo en el que la enseñanza de las ciencias se basa en las lecciones de cosas, se aplaza a los cursos superiores de primaria y se mantiene el rol de las niñas como cuidadoras, con otro que propone un plan organizado de formación en los primeros años y la formación pedagógica de todos los docentes.

Labor realizó con el Diccionario de pedagogía un gran esfuerzo colectivo por sistematizar muchas de las realizaciones modernizadoras y 
renovadoras que impulsaron las aulas republicanas, así como de las propuestas que se habían estado desarrollando y publicando desde hacía varios años. La omisión en el proyecto de Labor de una entrada sobre Lorenzo de Luzuriaga y del término paidología, así como la atención prioritaria que le concede a los estudios de enseñanza primaria, constituyen algunos sesgos de la obra.

En el Diccionario destacan las referencias a La naturaleza en la escuela de Rasmussen, cuyas ideas, publicadas en una fecha tan temprana como 1909, junto a las de profesores españoles como Margarita Comas, Dolores Cebrián y Rafal Candel llegaron a España gracias a la apertura a Europa que supusieron las ayudas de la JAE y a iniciativas de proyectos editoriales como el de Labor. Su modernidad, recogida por el Diccionario de pedagogía de 1936, nos suscita preguntas sobre las causas del olvido al que fueron relegadas estas aportaciones en las revisiones del estado de la didáctica de las ciencias durante la Transición española y la supuesta originalidad de la innovación educativa actual. Nos remiten a la idea inicial de este artículo: la necesidad de rescatar del olvido estos primeros pasos y recuperar nuestra memoria histórica, como una inestimable fuente de experiencias para la enseñanza de las ciencias.

\section{Nota sobre la autora}

Mavi Corell Domenech es licenciada en biología y doctora por la Universitat de València. Ha trabajado como periodista durante más de quince años. En su tesis doctoral investigó la divulgación de la ciencia en la revista La Ilustración Española y Americana (Madrid, 1869-1921). Desde 2013 ejerce como profesora de didáctica de las ciencias naturales en la Unidad de Educación de Florida Universitària (Catarroja, València). Sus intereses se centran en la historia de la enseñanza de las ciencias naturales durante la Segunda República y la Transición española.

\section{REFERENCIAS}

Aragón, Santiago, Carmen López y Francisco Javier Frutos, «La enseñanza a través de las imágenes del Instituto-Escuela». En Ciencia e innovación en las aulas. Centenario del Instituto-Escuela (1918-1939), editado por Martínez 
Alfaro, Encarnación, Leoncio López-Ocón y Gabriela Ossenbach Sauter, 121-146. Madrid: CSIC, 2018.

Asún Escartín, Raquel. «La editorial La España Moderna». Revista de la Facultad de Filología 31-32 (1981-1982): 133-199.

Barnés Salinas, Domingo. Paidología. Edición de José María Hernández Díaz. Madrid: Biblioteca Nueva, 2008.

Bensaude-Vincent, Bernardette, José Ramón Bertomeu-Sánchez y Antonio García Belmar. L'émergence d'une science des manuels. Les libres de chimie en France (1789-1852). París: Editions des Archives Contemporaines, 2003.

Bernal Martínez, José Mariano. Renovación pedagógica y enseñanza de las ciencias. Medio siglo de propuestas y experiencias escolares (1882-1936). Madrid: Biblioteca Nueva, 2001.

Casado Marcos de León, Ángel. «Filosofía y educación en España. Luzuriaga y la Revista de Pedagogía». BAJO PALABRA. Revista de Filosofía 6 (2011): 5362.

Comas, Margarita. Escritos sobre ciencia, género y educación. Editado por José M. Bernal y Francisca Comas. Madrid: Biblioteca Nueva, 2001.

Costa, Antón y María Eugenia Bolaño. «El Diccionario de Pedagogía de Labor, Barcelona (1936): la construcción icónico-textual de un discurso pedagógico ligado a los ideales de la Escuela Nueva». Cadernos de História da Educação 17, no. 2 (2018): 380-398.

Del Pozo Andrés, María del Mar. «La Escuela Nueva en España: crónica y semblanza de un mito». Historia de la Educación 22-23 (2003-2004): 317-346.

Delgado Martínez, M. ${ }^{a}$ Ángeles. Científicas y educadoras. Las primeras mujeres en el proceso de construcción de la Didáctica de las Ciencias en España. Murcia: Editum, Ediciones de la Universidad de Murcia, 2009.

Delgado Martínez, María Ángeles. Margalida Comas Camps (1892-1972), científica y pedagoga, editado por María Ángeles Delgado Martínez. Palma de Mallorca: Govern de les illes Balears, Conselleria d’Innovació, Interior y Justicia, 2014.

Fernández Soria, Juan Manuel. «La destrucción de la modernidad republicana. (Sin)razones del exilio pedagógico español». Historia y Memoria de la Educación 9 (2019): 61-99.

Ferrándiz, Alejandra, José C. Loredo y Enrique Lafuente. «Psicología y educación en la España de la II República: Un estudio a través del Diccionario de Pedagogía Labor (1936)». Revista de Educación 328 (2002): 451-463.

Frutos, Francisco, Carmen López-San Segundo, Beatriz González de Garay Domínguez y Manuela Carmona García. «La linterna de proyección y la renovación de la educación científica de los bachilleres españoles en el primer tercio del siglo XX». En Aulas abiertas. Profesores viajeros y renovación de la enseñanza secundaria en los países ibéricos (1900-1936), editado por 
Leoncio López-Ocón, Víctor Guijarro y Mario Pedrazuela, 219-252. Madrid: Universidad Carlos III de Madrid, 2018.

González Urbaneja, Pedro Miguel. «La historia de las matemáticas como recurso didáctico e instrumento para enriquecer culturalmente su enseñanza». Suma (febrero 2004): 17-28.

Guijarro Mora, Víctor. Artefactos y acción educativa. La cultura del objeto científico en la enseñanza secundaria en España (1845-1930). Madrid: Dykinson, 2018.

Guzmán, Miguel de. «Tendències innovadores en educació matemàtica». Butlletí de la Societat Catalana de Matemàtiques 7 (1992): 7-33.

Hernández Díaz, José María. «La pedagogía belga y la innovación educativa en España (1900-1936)». En Influencias belgas en la educación española e iberoamericana, editado por José María Hernández Díaz, 149-187. Salamanca: Ediciones de la Universidad de Salamanca, 2019.

Herrero, Fania, Alejandra Ferrándiz Lafuente y José Carlos Enrique y Loredo. «Psicología y Educación en la II República y en la España de Franco: un estudio a través del Diccionario de pedagogía de Labor $(1936,1964) »$. Revista de Historia de la Psicología 22, no. 3-4 (2001): 367-381.

Jiménez Artacho, Cristina, Joaquín Fernández Pérez y José Fonfría Díaz. «Iniciadores en España de la enseñanza ambiental de las ciencias naturales» (comunicación presentada al VIII Congreso de la Sociedad Española de Historia de las Ciencias y de las Técnicas, 2002).

Junqueira Lopes, Quintino Manuel. «Entre rupturas e continuidades. A Junta de Educação Nacional (1929-36) e a renovação pedagógica e científica liceal». En Aulas abiertas, editado por Leoncio López-Ocón, Víctor Guijarro y Mario Pedrazuela, 74-85. Madrid: Universidad Carlos III de Madrid, 2018.

Kaiser, David (ed.). Pedagogy and the Practice of Science. Historical and Contemporary Perspectives. Londres: MIT Press, 2005.

Kohlstedt, Sally G. «Nature, not Books. Scientist and the Origin of Nature-Study movement in the 1890's». Isis 96 (2005): 324-352.

Kohlstedt, Sally G. Teaching Children Science: Hand-on Nature Study in North America, 1890-1930. Chicago: University of Chicago Press, 2010.

López Martínez, José Damián y María Ángeles Delgado Martínez. «La enseñanza de las ciencias escolares en la Revista de Pedagogía (1922-1936)». Educació $i$ Història: Revista d'Història de l'Educació 24 (juliol-desembre, 2014): 69-101. López-Ocón, Leoncio, ed. Aulas modernas: Nuevas perspectivas sobre las reformas de la enseñanza secundaria en la época de la JAE (1907-1939). Madrid: Universidad Carlos III de Madrid, 2014.

López-Ocón, Leoncio. «Atlante: actores y etapas de una editorial republicana hispano-americana». En El exilio español del 39 en México. Mediaciones entre mundos, disciplinas y saberes, editado por Antolín Sánchez Cuervo y 
Guillermo Zermeño Padilla, 63-100. México, D.F.: El Colegio de México. Centro de Estudios Históricos, 2014.

López-Ocón, Leoncio. «La educación en la Segunda República (1931-1936): De visiones de conjunto a estudios de caso». En Política cultural de la segunda República, editado por Idoia Murga Castro y José María López Sánchez, 171-198. Madrid: Fundación Pablo Iglesias, 2016.

López-Ocón, Leoncio. «La trayectoria de 55 docentes de institutos españoles pensionados por la JAE». En Aulas abiertas. Profesores viajeros y renovación de la enseñanza secundaria en los países ibéricos (1900-1936), editado por Leoncio López-Ocón, Víctor Guijarro y Mario Pedrazuela, 443-454. Madrid: Universidad Carlos III de Madrid, 2018.

López-Ocón, Leoncio. «La enciclopedia de la editorial Atlante: un proyecto ¿frustrado? del exilio republicano en 1939». En Arte, ciencia y pensamiento del exilio republicano español de 1939, editado por Miguel Cabañas Bravo, Idoia Murga Castro, Miguel Ángel Puig-Samper y Antolín Sánchez Cuervo, 217-240. Madrid: Ministerio de la Presidencia, Relaciones con las Cortes y Memoria Democrática, 2020.

López-Ocón, Leoncio, Santiago Aragón y Mario Pedrazuela (eds.). Aulas con memoria. Ciencia, educación y patrimonio en los institutos históricos de Madrid (1837-1936). Madrid: Doce Calles, 2012.

Louv, Richard. Los últimos niños en el bosque. Madrid: Capitán Swing, 2018. Marín Eced, Teresa. «La pedagogía europea importada por los becarios de la JAE (1907-1937)». Historia de la Educación 6 (1987): 261-278.

Marín Murcia, José Pedro. «Categorización de los materiales didácticos para la enseñanza de los seres vivos en los antiguos gabinetes y laboratorios». Cabás 21 (junio 2019): 1-22. DOI: https://doi.org/ 10.35072/CABAS.2019.63.82.014

Marín Murcia, José Pedro y María José Martínez Ruiz-Funes. «Froebel and the teaching of botany: the garden in the Kindergarten Model School of Madrid». Paedagogica Historica 56, 1-2 (2020): 200-216.

Martínez Alfaro, Encarnación, Leoncio López-Ocón y Gabriela Ossenbach Sauter (eds.). Ciencia e innovación en las aulas. Centenario del Instituto-Escuela (1918-1939). Madrid: CSIC, 2018.

Martínez de Sousa, José. Antes de que se me olvide. Una aventura personal y bibliológica personal e intransferible. Gijón: Editorial Trea, 2005.

Mateos Montero, Julio. «Huellas pedagógicas alemanas en España. Una aproximación histórica». Magazin 20 (2011): 26-33.

Mayoni, María-Gabriela. «Dispositivos para la enseñanza de la naturaleza. Tecnología y modernidad en los colegios argentinos de finales del siglo XIX». Historia y sociedad, n. ${ }^{\circ} 40$ (enero-junio, 2021):171-97. https://doi.org/10.15446/ hys.n40.86795. 
Moreno Martínez, Luis. «Ciencia en las aulas: Prácticas pedagógicas, cultura material e historia de la ciencia en la obra de Modesto Bargalló en España (1894-1939)», PhD. diss, Universitat de València, 2020.

Moreno Martínez, Luis. «Modesto Bargalló en España (1894-1939): una biografía entre la historia de la educación y la historia de la ciencia». Historia y Memoria de la Educación 13 (2021): 635-674.

Olesko, Katherin. "Science Education in the Historical Study of Sciences». En International Handbook of research in History, Philosophy and Science Teaching, editado por Michael R. Matthews, 1965-1990. Dordrecht: Springer, 2014.

Pérez Hernández, Francisco Javier. Diccionarios, discursos etnográficos, universos léxicos: propuestas teóricas para la comprensión cultural de los diccionarios. Caracas: Fundación Centro de Estudios latinoamericanos Rómulo Gallegos; Universidad Católica André Bellos, 2000.

Pérez Hernández, Francisco Javier. Pensar y hacer el diccionario. Nociones de lexicografía: definiciones, géneros, crítica e historia. Criterios para elaborar diccionarios, métodos de investigación y bibliografía lexicográfica. Venezuela: Los Libros de El Nacional, 2005.

Rius Dalmau, María Inmaculada. «Institut-Escola de Barcelona (1931-1939)», Grup de Reçerca en Lingüística aplicada, Universitat Rovira I Virgili, http:// www.grelinap.recerca.urv.cat/ca/projectes/diccionario-historia-ensenanza-frances-espana/entradas/111/institut-escola-de-barcelona-1931-1939 (Recuperado el 9 de marzo, 2021)

Rudolph, John L. How We Teach Science? What's changed and why it matters. Cambridge, Massachusetts: Harvard University Press, 2019.

Sánchez Sarto, Manuel. Escritos económicos. México (1939-1969). Edición de Eloy Fernández Clemente. Zaragoza: Prensas Universitarias de Zaragoza, 2003.

Soler Mata, Joan. "La escuela activa de Adolphe Ferrière en la pedagogía española e iberoamericana». En Influencias suizas en la educación española e iberoamericana, editado por José María Hernández Díaz, 69-82. Salamanca: Ediciones de la Universidad de Salamanca, 2016.

Spencer, Herbert. Ensayos sobre Pedagogía. Madrid: Akal, 1983.

Valbuena Canet, Cecilia. «Georg Kerschensteiner y la escuela del trabajo: su introducción en España en el primer tercio del siglo XX a través de la figura de Lorenzo Luzuriaga». Foro de Educación 16, no. 25 (2018): 69-94.

Vilanou Torrano, Conrad. «Joaquín Roura Parella (1897-1983) y los orígenes de la Pedagogía Universitaria en Cataluña». En Pedagogía y Educación en el siglo XXI, editado por Julio Ruiz Berrio, 171-202. Madrid: Universidad Complutense, 2005.

Viñao, Antonio. "La historia de las disciplinas escolares». Historia de la Educación 25 (2006): 243-269. 